\title{
Vantagens do uso de tecnologias para criação, armazenamento e disseminação do conhecimento em bibliotecas universitárias ${ }^{1}$
}

\author{
Advantages of the use of technologies for creation, storage \\ and dissemination of knowledge in university libraries
}

Emeide Nóbrega DUARTE²

Alzira Karla Araújo da SILVA²

Edilene Galdino dos SANTOS ${ }^{3}$

Izabel França de LIMA²

Marcos Paulo Farias RODRIGUES ${ }^{4}$

Suzana Queiroga da COSTA ${ }^{4}$

\begin{abstract}
RES UMO
Com base em resultado de pesquisa que investigou, nas bibliotecas universitárias, entre outras questões, a dimensão tecnologia proposta pelo modelo de Organizações do Conhecimento apresentado por Angeloni, percebe-se que a tecnologia aplicada restringe-se ao uso das ferramentas Internet e Intranet para possibilitar a comunicação em redes. Identificou-se, portanto, o desconhecimento teórico das ferramentas data warehouse, groupware, workflow e gerenciamento eletrônico de documentos. Assim, busca-se destacar, no artigo, o papel da rede de computador - Internet, Intranet, Extranet, Data Warehouse, Groupware, Workflow e gerenciamento eletrônico de documentos - a fim de promover a aprendizagem, visando ao conhecimento conceitual de sua prática, rumo às organizações do conhecimento. Os bibliotecários, assim como outros profissionais da informação, atuam como gestores do conhecimento. Nesse sentido, devem adotar o uso da tecnologia da informação e suas ferramentas para facilitar o processo de criação, armazenamento e disseminação do conhecimento.
\end{abstract}

Palavras-chave: tecnologia; bibliotecas universitárias; gestão do conhecimento.

\section{A B STRACT}

Based upon research findings developed at University Libraries that he investigated, among others issues, the Dimension Technology proposed by the Knowledge Organizations model presented by Angeloni, it should be noted that the applied technology is limited to the use of Internet and Intranet tools to enable net communication. A theoretical unacquaintance of data, warehouse, groupware, workflow and electronic document management tools was therefore identified. In this article, the role of the Net, Internet, Intranet, Extranet, Data Warehouse, Groupware, Workflow, electronic document management is emphasized, in order to promote learning, aiming

- Artigo originado de projeto de pesquisa intitulado "A biblioteca universitária como organização do conhecimento: do modelo conceitual às práticas", financiado pelo $\mathrm{PIBIC/CNPq}$.

2 Professores, Departamento de Biblioteconomia e Documentação, Centro de Ciências Sociais Aplicadas, Universidade Federal da Paraíba. Campus I, João Pessoa, PB, Brasil. Corespondência para/Correspondence to: A.K.A. SILVA. E-mail: <alzirakarla@click21.com.br>.

3 Professores, Instituto de Ensino Superior da Paraíba. João Pessoa, PB, Brasil.

4 Acadêmicos, Faculdade de Biblioteconomia e Documentação, Centro de Ciências Sociais Aplicadas, Universidade Federal da Paraíba. João Pessoa, PB, Brasil.

Recebido em 23/9/2005 e aceito para publicação em 7/4/2006. 
at the conceptual knowledge of its practice, heading to knowledge organizations. Librarians, as well as other information professionals, act as managers of knowledge. Consequently, they must adopt the use of information technology and its tools to facilitate the creation process, storage and dissemination of the knowledge.

Key words: technology; university library; knowledge management.

\section{N T RO D U Ç Ã O}

Em pesquisa desenvolvida nas bibliotecas universitárias da Universidade Federal da Paraíba e do Centro Universitário de João Pessoa, que objetivava identificar até que ponto as bibliotecas universitárias se caracterizam como organizações que buscam trabalhar o conhecimento, Duarte et al. (2004) identificaram, entre outras questões, que a dimensão tecnologia, vem sendo trabalhada pelos profissionais da informação como ferramenta facilitadora do processo de comunicação.

A pesquisa ${ }^{5}$ que originou esse artigo teórico caracterizou-se como estudo de campo, de abordagem qualitativa de nível exploratório-descritivo; adotou como método o estudo de caso múltiplo e analisou uma situação particular, tendo como colaboradores os bibliotecários, apontados pelos gestores das duas bibliotecas como pessoas-chave das organizações. Nela adotou-se a técnica de grupo focal instrumentalizada por entrevista e observação direta em equipe, paralelamente. Esses instrumentos foram aplicados durante um encontro de "Integração de Equipes" intitulado "Chá de compartilhamento de conhecimento", que reuniu a equipe de bibliotecários da Universidade Federal da Paraíba (UFPB) e do Centro Universitário de João Pessoa (UNIPÊ), e tomou por base as dimensões infra-estrutura, pessoas e tecnologia do modelo proposto por Angeloni (2002). Para a análise, adotou-se a técnica de análise de conteúdo do tipo aberta, cujas categorias se formaram após a coleta de dados.

Considerando os resultados da pesquisa em foco, em relação à dimensão tecnologia, constatou-se que, nas bibliotecas universitárias estudadas, a tecnologia aplicada restringe-se ao uso das ferramentas Internet e da Intranet para possibilitar a comunicação em redes. No ambiente das bibliotecas, no que se refere ao uso de ferramentas tecnológicas tais como: data warehouse, groupware, workflowe gerenciamento eletrônico de documentos (GED), identificaram-se o desconhecimento das ferramentas data warehouse, groupware e workflow e uma informação básica sobre GED. Ressalta-se que, embora não se tenha registrado a adoção da GED no ambiente das organizações, essas ferramentas estão presentes no desempenho das atividades das bibliotecas analisadas, o que indica que os profissionais da informação em questão as adotam, mas sem o conhecimento teórico.

Apesar dos resultados constatados na pesquisa, Angeloni (2002) destaca o papel de novas ferramentas tecnológicas indicadas ao processo de criação, armazenamento e disseminação do conhecimento nas organizações. Assim, interessa destacar as vantagens de sua aplicação em bibliotecas universitárias, até então pouco conhecidas ou totalmente desconhecidas pelos profissionais da informação bibliotecários - de modo geral e, em particular, pelos das bibliotecas pesquisadas, a fim de promover a aprendizagem, visando ao conhecimento conceitual de sua prática, rumo às organizações do conhecimento.

\section{A TECNOLOGIAE OS PROFISSIONAISDA I N F O R M A Ç Ã O}

A tecnologia desempenha papel essencial na era do conhecimento, consistindo da adoção de técnicas e métodos que irão facilitar a captação, a estruturação e a disseminação do conhecimento, anteriormente desestruturado e disperso na organização ou restrito a poucas pessoas, por meio de manuais e normas complexas. Envolve a organização em novos domínios de atividades, tais como: busca de detalhes valiosos acerca de clientes, realização de simulações e geração de um negócio a partir do

\footnotetext{
5 Os resultados da pesquisa intitulada A biblioteca universitária como organização do conhecimento: do modelo conceitual às práticas estão publicados no VI ENANCIB, 2005.
} 
conhecimento em si - produtos ou processos baseados em tecnologias.

A tecnologia na organização do conhecimento, para Angeloni (2002, p.155),

[...] contribui fundamentalmente para a alavancagem dos processos de conversão do conhecimento - como socialização, externalização, combinação e internalização -, na medida em que possibilita a gestão do conhecimento intra e interorganizacional, geralmente sutil e de difícil criação, captação, transmissão e armazenamento.

A tecnologia deve ser aplicada de forma integrada e sistêmica à organização, buscando a sua integração com os indivíduos e sua expertise, pois "a simples aplicação da tecnologia não garantirá o sucesso de um projeto de gestão do conhecimento, tendo em vista a amplitude e a complexidade das demais dimensões existentes" (ANGELONI, 2002, p.155).

Nesse contexto, os seres humanos, em especial os profissionais da informação, são essenciais à transmissão do conhecimento, não como meros usuários do sistema, mas como responsáveis por sua alimentação ao trabalharem o ciclo de vida da informação, auxiliados pelo uso das tecnologias (NEVES; LONGO, 2001).

Os bibliotecários estão entre os poucos profissionais de uma organização que têm contato com pessoas de vários departamentos, entendendo as necessidades de conhecimento da organização. Por ser o atendimento aos clientes uma de suas tarefas básicas e por conhecer técnicas altamente desenvolvidas para encontrar a informação solicitada, esses fatores os fazem corretores naturais do conhecimento.

Numa perspectiva inovadora, no âmbito da economia política dos mercados do conhecimento, existem atores, como, por exemplo, os compradores do conhecimento - pessoas que geralmente estão tentando resolver um problema cuja complexidade e incerteza não permitem uma resposta fácil; os vendedores do conhecimento - pessoas da organização que têm reputação no mercado interno por possuir substancial conhecimento de um determinado processo ou assunto; e os corretores do conhecimento - pessoas conhecidas como guardiãs e demarcadores de área que colocam em contato compradores e vendedores: aqueles que precisam do conhecimento e aqueles que o possuem (DAVENPORT; PRUSAK, 1998).

Atuantes na "Sociedade da Informação e do Conhecimento", os bibliotecários freqüentemente agem como corretores do conhecimento disfarçados e apropriados, por seu temperamento e seu papel de guia de informações, para a tarefa de criar contatos pessoa-pessoa e pessoa-texto. Eles costumam explorar suas organizações, descobrir o que as pessoas fazem e quem sabe o quê; procuram entender o quadro maior, o que lhes permite saber onde obter o conhecimento, especialmente se tal conhecimento estiver fora de sua área oficial de responsabilidade.

O bibliotecário, assim como outros profissionais da informação, detêm os requisitos necessários para atuar como gestor do conhecimento, quais sejam: trabalhar com o ciclo de vida da informação (NEVES; LONGO, 1999-2000); administrar a quantidade imensurável de dados disponíveis a fim de transformá-los em informações relevantes para produção de conhecimento novo (SANTOS; MANTA, 2002); analisar a informação (qualidade, atualidade, precisão, relevância e valor) e encontrar, dentro das organizações, quem possa ajudar o usuário na busca de informação (McGEE; PRUSAK, 1994).

Assim, podem adotar o uso da tecnologia de informação e suas ferramentas para facilitar o processo de criação, armazenamento e disseminação do conhecimento, enfatizando o aspecto de como tornar o conteúdo do conhecimento atraente e como persuadir os seus detentores a disponibilizá-lo para socializá-lo. Entende-se então que, "na dimensão tecnologia, as variáveis consideradas inicialmente como suportes à engenharia do conhecimento são: redes de computadores (Internet, Intranet e Extranet), groupware, GED (gerenciamento eletrônico de documentos), workflowe data warehouse". (ANGELONI, 2002, p.155).

\section{A DIMENSÃO TECNOLOGIA A SERVIÇO D AS OR G A I Z A ÇÕ ES DO CONHECIMENTO: CONCEITOS E VANTAGENS}

Partindo da citação de Chiavegatto (2000, p.218): "já é sabido que não é a tecnologia, mas sim o seu uso apropriado que cria valor agregado, 
pois, na era do conhecimento, a capacidade de adquirir, tratar, interpretar e utilizar a informação de forma eficaz é que promove o diferencial estratégico", pertinente se faz compreender o papel da gestão do conhecimento nas mudanças organizacionais, bem como perceber a sua relação com as tecnologias de informação.

A aplicação de tecnologias tem sido feita com intuito de facilitar a manipulação e o uso das informações e do conhecimento nas organizações, possibilitando o cruzamento de dados e informações relevantes para a tomada de decisões. Dada a recente ascensão da gestão do conhecimento, resultados de pesquisas apontam modelos alternativos para construção de uma organização do conhecimento.

Angeloni (2002) define as organizações do conhecimento como aquelas voltadas para sua criação, seu armazenamento e seu compartilhamento por meio de um processo catalisador cíclico, a partir de três dimensões. No modelo proposto pela autora, a primeira dimensão em formato de átomo está relacionada à infra-estrutura organizacional, referindo-se à construção de um ambiente favorável ao objetivo da organização do conhecimento. A segunda dimensão refere-se às pessoas que, nas organizações do conhecimento, são profissionais qualificados, como afirmam Sveiby (1998), Stewart (1998) e Davenport e Prusak (1998), estando relacionada a características necessárias às atividades do conhecimento. A terceira dimensão diz respeito à tecnologia, funcionando como um suporte para a criação, disseminação e armazenamento do conhecimento. Assim, tida como ferramenta importante no processo de gestão do conhecimento, deve ser reconhecida e implantada nas organizações do conhecimento, de modo que descrevemos seus principais conceitos e aplicações nessas organizações, mais especificamente nas bibliotecas, destacando as vantagens dessas ferramentas.

Redes de computadores são "um conjunto de meios de comunicações, dispositivos e softwares necessários para conectar dois ou mais sistemas ou dispositivos de computador" (PEREIRA, 2002, p.160), favorecendo um baixo custo para ligar gerentes $\mathrm{e}$ funcionários.

Para Castells (2000, p.185), "as redes são e serão os componentes fundamentais das organizações [...] porque contam com o poder da informação propiciado pelo novo paradigma tecnológico". O estabelecimento de novas formas de gerenciamento nas organizações é uma realidade em função das redes, constituindo

um conjunto de nós interconectados. Nó é o ponto no qual uma curva se entrecorta. Redes são estruturas abertas capazes de expandir de forma ilimitada, integrando novos nós desde que consigam comunicar-se dentro da rede, ou seja, desde que compartilhem os mesmos códigos de comunicação. (CASTELLS, 2000, p.498).

Captar, gerenciar, armazenar e permitir uma retroalimentação constante do conhecimento é o desafio das modernas teorias empresariais, as quais vêem na tecnologia uma aliada na administração dos volumes e formas diversas desse recurso organizacional. Redes de computadores são uma verdadeira forma de organização que altera as práticas de comunicação entre os atores e a maneira como a informação e o conhecimento fluem dentro da organização. Nesse sentido, Castells (2000, p.185) enfatiza que,

para operar na nova economia global, caracterizada pela onda de novos concorrentes que usam novas tecnologias e capacidades de redução de custos, as grandes empresas tiveram de tornar-se principalmente mais efetivas que econômicas. As estratégias de formação de redes adotaram os sistemas de flexibilidade, mas não resolveram o problema da adaptabilidade da empresa. Para conseguir absorver os benefícios da flexibilidade das redes, a própria empresa teve de tornar-se uma rede e dinamizar cada elemento de sua estrutura interna.

Essa tecnologia permite compartilhar hardware, softwares, bancos de dados e faz com que grupos de trabalho geograficamente distantes compartilhem trabalhos, projetos, idéias, opiniões, criando uma infra-estrutura potencial para o intercâmbio de informações e conhecimentos (PEREIRA, 2002).

As redes criam uma infra-estrutura potencial para o intercâmbio de informações e conhecimentos, possibilitando, segundo Pereira (2002): conectar dois ou mais sistemas, permitindo compartilhar conhecimentos à distância; alterar as práticas de comunicação e a maneira de como a informação e o conhecimento fluem dentro da organização; oferecer 
níveis de qualidade e prestação de serviços superiores em decorrência do livre fluxo de informações; aumentar a interação e o aprendizado das pessoas, contribuindo para novos conhecimentos; favorecer a criação de mercados virtuais de conhecimento.

Internet de acordo com Castells (2000, p.181), "[...] a comunicação on line e a capacidade de armazenagem computadorizada tornaram-se ferramentas poderosas no desenvolvimento da complexidade dos elos organizacionais entre conhecimentos tácitos e explícitos". Assim, "a Internet é uma meta-network internacional de redes colaborativas multiprotocolos, interconectadas, que suportam a colaboração entre milhares de organizações" (PEREIRA, 2002, p.162). A Internet, "rede das redes", vem conquistando espaço na classe empresarial, estimando-se que praticamente todo tipo de atividades esteja descobrindo seus benefícios significativos.

Na gestão do conhecimento, a Internet vem servindo como base para diversos programas e ambientes que propiciam a captação, o armazenamento e principalmente a difusão dos conhecimentos, impondo novas formas de organização que incluem desde os relacionamentos mais próximos com fornecedores e clientes até a integração virtual da empresa com outras entidades. Contudo, na sua utilização, há o problema do julgamento do conhecimento fornecido, uma vez que o volume de informações é muito elevado e acaba obscurecendo o que é realmente relevante, surgindo assim os corretores ou bibliotecários da Internet com reputação para localizar material de relevância e qualidade.

Entre os serviços disponíveis, têm-se os grupos de discussão como uma ferramenta importante de aprendizado e criação de conhecimento, cuja interatividade faz a diferença, permitindo às pessoas obterem informações, tirar dúvidas em tempo real, aprender em grupo, por meio de questionamentos e percepções diversas, inevitavelmente concorrendo tanto para o desenvolvimento de novos conhecimentos para a empresa como para sua difusão. Já por meio das homepages, as empresas podem ir além da comercialização de produtos, realizando pesquisa e estabelecendo canais diretos com os clientes, os quais, além de fidelidade, trazem consigo, embutidos nas reclamações, elogios e pedidos, conhecimentos úteis acerca das suas necessidades e desejos com relação à empresa.

Na Internet, podem ser disponibilizados ainda páginas amarelas ou mapas do conhecimento. As Páginas Amarelas ou Mapas do Conhecimento

São bancos de dados on line de funcionários portadores do conhecimento, acessíveis a todos os usuários para pesquisa, localização e comparação de fontes potenciais do conhecimento. [...] Seu principal objetivo, e benefício mais evidente, é indicar às pessoas da empresa para onde ir quando necessitarem do conhecimento. (PEREIRA, 2002, p.165).

A ligação da organização em redes facilita a integração, o compartilhamento, o armazenamento, a disseminação e o acesso ao conhecimento. Através de uma Internet, por exemplo, a organização pode interligar pessoas e unidades, fazendo o conhecimento fluir, possibilitando também sua criação. Assim, baseando-nos em Pereira (2002), destacamos, entre suas vantagens, as seguintes: servir de suporte para outras ferramentas tecnológicas, facilitando a cooperação e a criação de redes de informação; servir como base para programas e ambientes que propiciam a captação, o armazenamento e a difusão dos conhecimentos por meios de terminais on line, favorecendo a interação dos indivíduos e colaborando com a criação do conhecimento; representar um sistema de organização que revoluciona os processos, contendo barreiras entre biblioteca, usuários e fornecedores; possibilitar que a pesquisa de um assunto traga resultados de todo o sistema; permitir a inclusão de corretores ou bibliotecários para localizar material de relevância e qualidade; fornecer o serviço de grupo de discussão, importante para o aprendizado e a criação do conhecimento; facilitar a comunicação interorganizacional, sites interativos na rede, e-mail, BBS, grupos de discussão, áudio e videoconferência e outros dispositivos da Internet; permitir pesquisa, solicitação, disseminação e compartilhamento de informações comerciais internas e externas, fazendo com que pessoas e membros de diferentes organizações em diferentes locais trabalhem juntos.

Esses repositórios de conhecimento "são conjuntos de conhecimentos explícitos estruturados, obtidos de fontes internas e externas" (PEREIRA, 2002, p.165). Relacionadas à Internet, temos ainda as redes de computadores Intranet e Extranet, conforme segue: 
Intranet: "são soluções de redes privadas e completas que permitem o gerenciamento de informações necessárias à organização por meio de processos e protocolo na Internet" (PEREIRA, 2002, p.166). Como exemplo, destaca-se o Knowledge Exchange, um sistema interligado por meio de Intranet que reúne todo o conhecimento desenvolvido pela consultoria da Anderson Consulting, armazenando todos os projetos globais da empresa e permitindo aos profissionais consultar dados, fazer perguntas a outros que passaram por situações semelhantes. Dessa forma, a Intranet é uma "[...] forma das pessoas terem acesso aos projetos atuais, evitando a duplicação de trabalhos semelhantes e permitindo que as pessoas com afinidades em suas tarefas entrem em contato com outros profissionais e discutam novas idéias". (PEREIRA, 2002, p.167).

Dentre as vantagens da Intranet, destacam-se: a possibilidade de maior aproveitamento da inteligência da organização, pois permite aos usuários criar, acessar e distribuir informações facilmente; a contribuição com as novas tecnologias, possibilitando a externalização do conhecimento e tornando explícito o conhecimento tácito; o fato de ser projetada para ser uma rede aberta, segura e interna, cujo software de navegação fornece acesso fácil de tipo apontar e clicar para usuários finais acessarem informações em multimídia em site de rede interna; de possuir um alcance mundial na organização como um todo; de oferecer acesso por meio de guia fácil e interativo via navegação de rede; de ter acesso, software e hardware de baixo custo; de transferir arquivos padronizados; de criar padronização de documentos; de ser executável em todas as plataformas; de reduzir custos com papel, impressão, marketing e vendas; $\mathrm{e}$ de aumentar a produtividade via acesso rápido à informação e colaboração mais fácil. utilizar a Internet como parte das conexões de rede. Torna mais fácil a clientes e fornecedores o acesso a recursos Intranet, facilitando um processo on line e interativo de desenvolvimento de produto e um processo voltado para o cliente, que pode levar mais depressa para o mercado produtos mais bem projetados. Dentre suas vantagens e aplicações, agiliza a transmissão de dados, descentralizando atividades e transferindo competências e organiza a combinação do conhe-cimento.

Outras ferramentas citadas por Angeloni (2002) são Workflow, Groupware, Data warehousing eGED:

Workflow: conhecida genericamente como uma tecnologia para trabalho em grupo, é uma ferramenta que possibilita um trabalho integrado, cooperativo e ativo (DUARTE; SZOSTAK, 2000). Compreende o método e o conjunto de softwares para automatizar e organizar o fluxo de documentos numa organização, pondo em fila, com flexibilidade, e-mails, memorandos, relatórios e autorizações. Essa ferramenta tecnológica possibilita a captação da "inteligência" de um determinado processo por meio de sua geração, controle e automatização. "É a tecnologia que possibilita automatizar processos, racionalizando-os e potencializando-os por meio de dois componentes: organização e tecnologia" (PEREIRA, 2002, p.166). Sistematiza o fluxo de documentos, facilitando o conhecimento com a democratização de rotina, expondo avaliações e críticas dos envolvidos. Workflow, de forma mais abrangente, é um tipo de Sistema de Informação.

Essa tecnologia, de acordo com Setti (2000), vem emergindo como viabilizadora das mudanças nas corporações, pois se diferencia quando codifica, aplica regras, processos e melhores práticas, tornando-se a base para a integração de aplicações existentes e de novas aplicações. O autor cita, dentre essas aplicações, processos específicos envolvendo áreas da Tecnologia da Informação, como Sistemas Integrados de Gestão Empresarial (ERP), Comércio Eletrônico e Gerenciamento das Relações com Clientes (CRM).

Baseando-se na dinâmica integrada e orientada para processos, Thom et al. (2000, p.280) consideram que, para o desenvolvimento de um sistema de workflow, recomenda-se conhecer a dinâmica da organização, verificando o modo de 
trabalho e a forma de comunicação entre as áreas da organização, auxiliando na qualidade do produto final. Assim, "um sistema de Workfow é capaz de descrever cada tarefa de um processo de negócio em um nível conceitual que facilita o entendimento, a avaliação e a reengenharia dos processos" (THOM et al., 2000, p.282).

Considerando que os sistemas de Workflow são projetados para automatizar processos, podem e devem ser aplicados como ativo diferencial na conversão do conhecimento tácito em explícito, proporcionando automação de processos e facilitando o fluxo de trabalho.

Suas vantagens, de acordo com Trives Júnior (2002), são: integração de política de administração; maior agilidade nos processos técnicos, oferecendo ao usuário a informação em menor tempo; comunicação entre os funcionários sobre as atividades feitas e seqüências das posteriores; minimização do desperdício de tempo; aumento da satisfação dos usuários, pois oferece agilidade nos documentos e consenso nas informações oferecidas; comunicação sobre os fatos ocorridos e próximos eventos (biblioteca); maior controle dos serviços oferecidos e executados; e visão do "todo".

Essa tecnologia, aliada à gestão do conhecimento,

[...] permite às organizações a automatização dos relacionamentos entre os usuários, informações e processos; o compartilhamento da experiência e especialização dos colaboradores da instituição; contribui para o gerenciamento do ambiente tecnológico na conversão do conhecimento em suas quatro fases: socialização, externalização, combinação e internalização. (TRIVES JÚNIOR, 2002, p.193).

É uma ferramenta de apoio à gestão do conhecimento; transforma o conhecimento organizacional, de tácito para explícito, permitindo sua disseminação, compartilhamento e aprendizado por todos; automatiza os processos organizacionais, buscando agilizá-los, determinando um diferencial competitivo; possibilita o trabalho em grupo de forma integrada, interativa e ativa; registra a sucessão de tarefas necessárias para processar documentos numa organização; permite às organizações construírem fluxos de trabalho automatizados, diminuindo o tempo gasto e melhorando a comunicação com os clientes; permite o acesso rápido e compartilhado das informações referentes ao funcionamento e à estrutura dos processos da organização de forma estruturada, oportuna e íntegra; possibilita que as informações permaneçam registradas por meio da tecnologia da informação; possibilita a transformação do conhecimento nas organizações; indiretamente estimula os processos de interação e transformação do conhecimento (socialização, externalização, combinação e internalização), conforme vemos no quadro 1.

Essas tecnologias trabalhadas por Angeloni (2002) e representadas no quadro podem ser aplicadas nos quatro processos de conversão do conhecimento (NONAKA; TAKEUCHI, 1997). Na internalização, processo de incorporação do conhecimento explícito para tácito, o data warehousing vem facilitar o processo de assimilação por meio do acesso ao armazém de dados formado a partir das informações nele registradas. Na socialização, processo de compartilhamento de experiências, a ferramenta Intranet permite que pessoas com interesses comuns encontrem outros profissionais e discutam novas idéias; o workflowauxilia a conversão do conhecimento tácito em tácito; e o groupware vem facilitar o trabalho em grupo e, conseqüentemente, o compartilhamento do conhecimento tácito entre as pessoas. Com relação à externalização, articulação do conhecimento tácito em conceitos explícitos, a Intranet, o workflowe a GED podem ser utilizados para a exteriorização do conhecimento organizacional. Por fim, no processo de combinação, união

Quadro 1. Os quatro processos de conversão do conhecimento.

\begin{tabular}{lccc}
\hline Internalização & Socialização & Externalização & Combinação \\
\hline Data Warehousing & Intranet, Workflow, Groupware & Intranet, GED & Workflow, Extranet \\
\hline
\end{tabular}

Fonte: Baseado em Nonaka e Takeuchi (1997) e Angeloni, (2002). 
de diferentes conhecimentos explicitados, a Extranet permite à organização a sistematização e harmonização do conhecimento.

Groupware: "é o nome dado ao uso das tecnologias de informação como suporte ao trabalho em grupo, tais como reuniões e trabalhos de equipes à distância" (PEREIRA, 2002, p.166). É um software que ajuda grupos a trabalharem juntos na execução de tarefas; suporta a colaboração por meio de correio eletrônico, grupos de discussões e bancos de dados, agendamento, gerenciamento de tarefas, conferências com dados, áudio e vídeo, etc.

O Groupware destina-se a tornar significativamente mais fáceis a comunicação e a coordenação das atividades dos grupos de trabalho e a cooperação entre os usuários finais, em qualquer lugar que os membros de uma equipe estejam localizados, ajudando-os a colaborarem com projetos de grupo no mesmo momento ou em momentos diferentes e no mesmo lugar ou em diferentes localizações.

Caracterizada como uma tecnologia de base de apoio para o trabalho em grupo de pessoas, separadas ou unidas pelo tempo e espaço, constitui-se uma interface do compartilhamento do conhecimento que facilita a comunicação e coordenação das atividades em grupo, e a cooperação entre os usuários finais independe de sua localização.

Data warehousing: processo pelo qual as empresas extraem sentido e significado dos seus dados por meio da utilização de bancos de dados. É um sistema que guarda e organiza todas as informações que estão espalhadas por vários sistemas dentro de uma organização. Armazena dados do ano em curso e dos anos anteriores que foram extraídos dos vários bancos de dados operacionais de uma organização. É uma fonte central de dados que foram classificados, editados, padronizados e integrados de tal forma que podem ser utilizados por gerentes e outros profissionais usuários finais em forma de análise organizacional, pesquisa de mercado e apoio à decisão. A tecnologia de data warehouse vem, portanto, sendo implantada como "[...] um conjunto de dados baseado em assuntos, integrado, não volátil e variável em relação ao tempo, de apoio às decisões gerenciais" (ALMEIDA, 2002, p.174). Como um armazém de dados, recebe-os de toda a organização, associando-os a novas ferramentas e possibilitando encontrar correlações entre eles, favorecendo uma visão holística que proporciona uma integração no trabalho.

Diferente dos dados operacionais, os quais passam por operação contínua de inclusão, exclusão e acesso, os dados residentes em Data Warehousing são apenas acessados e esporadicamente atualizados. Organizando os dados, podemos recuperá-los de forma estratégica e direta; pequenas informações em uma organização podem ser garimpadas e entregues ao gestor. Na biblioteca, por exemplo, informações como a hora que tem a maior concentração no setor de empréstimo ou os serviços que têm menos procura em determinado dia ou horário seriam de grande importância para o gestor, pois, com essas informações, é possível remanejar ou oferecer treinamentos aos colaboradores.

Têm sido incorporadas aos data warehouses ferramentas de busca de informações como o data mining, o qual fornece memória à organização "[...] são softwares desenvolvidos com base em técnicas de inteligência artificial, que vasculham os dados em busca das informações que podem ser de interesse, de acordo com os critérios predeterminados" (ALMEIDA, 2002, p.178). Ou seja, "[...] é a exploração e a análise de grandes quantidades de dados para descobrir modelos e regras significativas" (ALMEIDA, 2002, p.178).

Para uma aplicação específica, as organizações podem empregar os data marts, que fornecem informações de toda a organização, encontram informações necessárias a uma unidade ou função específica.

As vantagens do data warehouse, de acordo com Almeida (2002), são: reunir em um grande banco de dados todos os registros sobre a organização; ser associado a ferramentas de busca (OLAP e data minings); obter informações relevantes e integradas que geram conhecimento; permitir ao dirigente desenvolver uma visão holística da organização, levando-o a uma tomada de decisão com maior segurança; possibilitar que as decisões sejam tomadas com base em informações e conhecimentos da organização; ao armazenar dados associando-os a um período de tempo em que ocorreram, criar um histórico de desempenho organizacional, podendo ser utilizado para compreender o passado e predizer comportamentos futuros; algumas respostas passam a ser visualizadas em poucos minutos; o fato de um 
de seus recursos ser a análise multidimensional, que permite ao usuário acessar o sistema a partir de qualquer dimensão; fazer cruzamento de dados desconexos por meio de ferramentas de buscas, gerando respostas rápidas; associado ao data mining, fazer mineração correlacionando os dados e adotando o data mart, banco de dados específico de uma área, proporcionando maior segurança em sua implantação ao permitir iniciar por uma unidade ou função/módulo de negócios.

Gerenciamento eletrônico de documentos: significa gestão eletrônica de documentos que reagrupam informações, facilitando seu arquivamento, acesso, consulta e difusão, tanto internamente como externamente. Vem facilitar o fluxo de informações e conhecimento nas organizações de forma eletrônica, facilitando o arquivamento, o acesso, a consulta e a difusão desses documentos e informações. Possibilita, portanto, de acordo com Machado (2002), não só arquivar, mas tratar as informações contidas nos documentos; propõe modos alternativos para a utilização de informações documentárias. 0 GED permite, portanto,

Evitar a duplicação abusiva de documentos; classificar segundo diversos critérios cruzados; autorizar o acesso a informações e conhecimentos pertinentes; conter dados não vinculados por papel, como vídeo-som; acabar com o problema de tempo e lugar; implementar novos modos de navegação não-linear; permitir e melhorar a segurança e a perenidade dos arquivos. (MACHADO, 2002, p.197).

Visa gerenciar o ciclo de vida das informações e dos conhecimentos desde sua criação até seu arquivamento; permite o armazenamento em mídias digitais e eletrônicas; possibilita o gerenciamento de imagens de documentos, arquivos oriundos de editores de textos, planilhas e outras formas de documentos; visa apontar todas as propriedades do documento; facilita a entrega da informação certa à pessoa certa no tempo certo.

Após visualizarmos essas vantagens, ressaltamos ainda que a gestão do conhecimento é uma questão essencialmente de pessoas e processos. Muitas organizações têm se frustrado com seus investimentos em comunicações e redes, geralmente voltados para groupware, correio eletrônico, videoconferência etc. Fora da perspectiva da gestão do conhecimento, por exemplo, a adoção de groupware tem fracassado ao favorecer o trabalho realmente de equipe, gerando apenas intermináveis listas de discussão pouco úteis para a empresa. Da mesma forma, é fácil prever que a proliferação de intranets vai gerar principalmente inúmeros pequenos web sites nas organizações, que adicionarão pouco valor aos negócios (TEIXEIRA FILHO, 2001).

Assim, as tecnologias úteis para a gestão do conhecimento são aquelas que propiciam a integração das pessoas, que facilitam a superação das fronteiras entre unidades de negócio, que ajudam a prevenir a fragmentação das informações e permitem criar redes globais para o compartilhamento do conhecimento. Isso é fundamental, por exemplo, para a criação de bases de dados de clientes e para o entendimento do comportamento do usuário. Com base nesse percurso teórico, identificamos as aplicações dessas tecnologias nas organizações do conhecimento.

\section{CONSIDERAÇÕES FINAIS}

Considerando as perspectivas teóricas das tecnologias propostas no Modelo de Angeloni (2002) e as suas vantagens, destaca-se a possibilidade de sua aplicação em bibliotecas, a serem consideradas organizações do conhecimento. Dessa forma, sugerem-se as possíveis aplicações da tecnologia em bibliotecas universitárias.

Relacionada ao uso de redes a sua aplicação pode permitir a cooperação entre bibliotecas de interesses comuns, evitando a duplicação de esforços e o compartilhamento de acervos. Outro beneficio é disponibilizar ao usuário final informações por meio do compartilhamento de arquivos e o seu acesso por meio do correio eletrônico, de homepages, páginas pessoais e a comunicação com usuários e fornecedores.

Com o uso da Internet é possível a disponibilização do acervo, a realização do serviço de referência virtual, a agilidade no empréstimo e devolução de documentos, a recuperação seletiva da informação, a disseminação seletiva de informação, a criação de bibliotecas virtuais, a disponibilização de informação eletrônica, a prestação de informações gerenciais sobre a biblioteca, o acesso 
ao correio eletrônico, a prestação de serviço de alerta, a criação de grupo de notícias ou discussões, a disponibilização de bases de dados on line, a facilitação da cooperação entre bibliotecas e a viabilização de redes de bibliotecas.

A Intranet por sua vez permite o compartilhamento interno de informações e procedimentos relativos aos colaboradores e suas atividades; possibilita uma rede interna de comunicação entre os setores da biblioteca; permite a visão sistêmica, uma vez que na Intranet está refletida a estrutura da biblioteca; facilita a identificação de pessoas e sua alocação, permitindo assim o acesso a informações internas.

Com a adoção da Extranet haverá o compartilhamento de informações entre biblioteca e fornecedor, biblioteca e cliente, biblioteca e biblioteca, formando um sistema viável para o processo de aquisição e permuta.

A ferramenta Workflow proporcionará a transformação do conhecimento tácito em explícito ao transferir informações e conhecimento ao longo do processo de trabalho.

Facilita o fluxo e a rotina de trabalho, bem como o processo de aquisição de documentos e os processos técnicos.

A tecnologia de Groupware quando adotada forma grupos de trabalho para intercâmbio do conhecimento (comunidade de prática), possibilitando trabalhar em equipe; facilita, assim, o trabalho em

\section{REFERÊNCIAS}

ALMEIDA, M.S. Gestão do conhecimento e data warehouse: alavancagem no processo decisório. In:ANGELONI, M.T. Organizações do conhecimento: infra-estrutura, pessoas e tecnologia. São Paulo: Saraiva, 2002. Cap.11, p.172-184.

ANGELONI, M.T. (Coord.). Organizações do conhecimento: infra-estrutura, pessoas e tecnologia. São Paulo: Saraiva, 2002. $215 p$.

CASTELLS, M. A empresa em rede: a cultura, as instituições e as organizações da economia informacional. In: CASTELLS, M. A sociedade em rede. 4.ed. São Paulo: Paz e Terra, 2000. Cap.3, p.173-221.

CHIAVEGATTO, M.V. As práticas do gerenciamento da informação: estudo exploratório na Prefeitura de Belo Horizonte. In: SIMPÓSIO INTERNACIONAL DE GESTÃO DO CONHECIMENTO/GESTÃO DE DOCUMENTOS (ISKM/DM), 3., 2000. Anais...Curitiba: PUCPR/CITS, 2000. grupo entre bibliotecas cooperantes que formam um sistema e compartilham uma rede.

O Data Warehousing, ferramenta que contribui para traçar perfil do usuário para Disseminação Seletiva da Informação, é adotado para biblioteca de acervo geral, proporcionando atendimento personalizado aos clientes na tomada de decisão no processo de desenvolvimento das coleções. Pode ser adotado no processo técnico, bem como permitir identificar os horários de mais freqüência aos serviços, possibilitando remanejamento de pessoal (rodízio).

A tecnologia GED como ferramenta tecnológica de gerenciamento documental possibilita gerenciar a produção científica da universidade, (artigos, teses, dissertações, relatórios técnicos, documentos administrativos entre outros), bem como promover a perenidade de coleções de obras raras. A GED permite gerenciar o ciclo de vida das informações e dos conhecimentos desde sua criação até o seu arquivamento. Constitui-se, portanto, um repositório de documentos corporativos, permitindo acesso a manuais e documentos históricos (conhecimento explícito).

Considerando as possíveis aplicações e vantagens da tecnologia para as bibliotecas universitárias, é relevante que elas maximizem seu uso, facilitando a criação, o armazenamento e a disseminação de informações para a construção do conhecimento, cumprindo eficientemente o objetivo intrínseco às unidades de informação.

DAVENPORT, T.H.; PRUSAK, L. Conhecimento empresarial. 5.ed. Rio de Janeiro: Campus, 1998. 237p.

DUARTE, E.N. et. al. (Coord.). A biblioteca universitária como organização do conhecimento: do modelo conceitual às práticas. Relatório Parcial. João Pessoa, Departamento de Biblioteconomia e Documentação, 2004. Relatório parcial do projeto de pesquisa financiado pelo CNPq.

DUARTE, D.; SZOSTAK, R. A tecnologia WAP na Gestão do Conhecimento. In: SIMPÓSIO INTERNACIONAL DE GESTÃO DO CONHECIMENTO/GESTÃO DE DOCUMENTOS (ISKM/DM), 3., 2000. Anais... Curitiba, PUCPR/CITS, 2000.

MACHADO, R.B. Gerenciamento eletrônico de documentos e sua inter-relação com a gestão do conhecimento. In: ANGELONI, M.T. Organizações do conhecimento: infra-estrutura, pessoas e tecnologia. São Paulo: Saraiva, 2002. Cap.13, p.196-210. 
McGEE, J.; PRUSAK, L. Gerenciamento estratégico da informação. Rio de Janeiro: Campus, 1994. 244p.

NEVES, E.C.; LONGO, R.M.J. Atuação do profissional da informação na gestão do conhecimento. In: ISKM, 2., 2001. Anais... Curitiba: PUCPR/CITS, 2001.

NEVES, E.C.; LONGO, R.M.J. Atuação do profissional da informação na gestão do conhecimento. Revista de Biblioteconomia de Brasília, Brasília, v.23/24, n.2, p.161-172, 1999-2000.

NONAKA, I.; TAKEUCHI, H. Criação de conhecimento na empresa. 7.ed. Rio de Janeiro: Campus, 1997. 357p.

PEREIRA, R.C.F. As redes como tecnologias de apoio à gestão do conhecimento. In: ANGELONI, M.T. Organizações do conhecimento: infra-estrutura, pessoas e tecnologia. São Paulo: Saraiva, 2002. Cap.10, p.156-171.

SANTOS, A.R.; MANTA, L.D. O bibliotecário na sociedade da informação brasileira. In: CONGRESSO BRASILEIRO DE BIBLIOTECONOMIA, DOCUMENTAÇÃO E CIÊNCIA DA INFORMAÇÃO, 2002, Fortaleza. Anais... Fortaleza: 2002.

SETTI, M. et al. Projeto businexpress: um workflow para web, modular e integrável. In: SIMPÓSIO INTERNACIONAL DE
GESTÃO DO CONHECIMENTO/GESTÃO DE DOCUMENTOS (ISKM/DM), 3., 2000. Anais... Curitiba, PUCPR/CITS, 2000. 528p.

STEWART, T.A. Capital intelectual: a nova vantagem competitiva das empresas. Rio de Janeiro: Campus, 1998. 280p.

SVEIBY, K.E. A nova riqueza das organizações: gerenciando e avaliando patrimônios de conhecimento. Rio de Janeiro: Campus, 1998. 237p.

TEIXEIRA FILHO, J. Tecnologia da informação para a gestão do conhecimento. Disponível em: <http://www.infotmal. com.br/artigos/art008.htm>. Acesso em: 27 maio 2001.

THOM, L.J. et al. Processo de desenvolvimento de sistemas de workflow considerando fatores humanos e a análise da dinâmica organizacional. In: SIMPÓSIO INTERNACIONAL DE GESTÃO DO CONHECIMENTO/GESTÃO DE DOCUMENTOS (ISKM/DM), 3., 2000. Anais... Curitiba: PUCPR/CITS, 2000.

TRIVES JÚNIOR, J.J. A tecnologia de workflow e a transformação do conhecimento. In: ANGELONI, M.T. Organizações do conhecimento: infra-estrutura, pessoas e tecnologia. São Paulo: Saraiva, 2002. Cap.12, p.185-195. 
